\title{
Media Awareness and Utilization of Antenatal Care Services by Pregnant Women in Kano State- Nigeria
}

\author{
Hajara Umar Sanda \\ Department of Mass Communications, Bayero University, Nigeria \\ E-mail: husanda2003@yahoo.com
}

Received: November 23, 2013 Accepted: February 18, 2014 Published: February 24, 2014

doi:10.5296/jsss.v1i2.5175 URL: http://dx.doi.org/10.5296/jsss.v1i2.5175

\begin{abstract}
This study explores pregnant women's major sources of information on Antenatal Care services (ANC), their media preferences of ANC programmes, their appropriate timing as well as the challenges they face in use of the media in Kano state. The study was informed by the inadequacy of health information from the media, which results to the under-utilization of ANC services by pregnant women. This has serious negative implications on maternal health and mortality. Focus group discussion was the main methodology used in the study and was complimented with In-depth interviewing and document analysis. Findings reveal that the dominant theme was the use of Radio as the major source of information on ANC services as well as other sources like health workers and social gatherings among others. In addition, the pregnant women demonstrated good knowledge and awareness of ANC services but some of them do not attend ANC even though they are aware while others are not even aware at all, of the importance of utilizing ANC services. The data further shows that the pregnant women preferred media programmes in which a health expert discusses ANC and maternal health issues. Similarly, their preferred timing for the ANC programmes is $4.00 \mathrm{pm}$ and they shared substantial challenges which tend to inhibit their media usage, which influences ANC utilization. The study recommends that media ANC programmes should target men as partners in progress in all matters related to maternal health. Also, the government and other wealthy individuals should establish more community radios with priority to ANC and health related programs.
\end{abstract}

Keywords: Media Awareness, Utilization, Antenatal, Maternal Health, Antenatal Health Care, Health Communication, Kano 


\section{Introduction and Background to the Study}

It has been estimated that about 536, 000 pregnant women die every year out of which $99 \%$ $(533,000)$ take place in third world countries in which Sub-Saharan Africa and Southern Asia accounts for $86 \%$ of these deaths (World Health Organization (WHO), 2007). Globally, Africa has one of the highest maternal deaths and sub-Saharan Africa is the worst affected with an estimated figure of $98 \%$ of maternal deaths (WHO, 2007; Babalola \& Fatusi, 2009). Similarly, the World Health Organization (WHO), the United Nations Children's Fund (UNICEF), the United Nations Population Fund (UNFPA) and the World Bank (2010) estimate reveal that the lifetime risk of maternal deaths in the developing world in 2008 as a whole was 1 in 120 compared with an estimated 1 in 4300 in the industrialized regions. Among the regions, women in sub-Saharan Africa face the highest lifetime risk of 1 in 31, followed by South Asia 1 in 110 as depicted in Table 1 below:

Table 1. Adult Lifetime risk of Maternal Death, 2008

Region

\begin{tabular}{cc} 
Region & Death: $\mathbf{1}$ in : \\
\hline Sub-Saharan Africa & 31 \\
South Asia & 110 \\
Middle East and North Africa & $\mathbf{1 9 0}$ \\
East Asia and the Pacific & 600 \\
Central Eastern Europe/Commonwealth of & 1700 \\
Independent States & 4300 \\
Industrialized regions & 480 \\
Latin America and the Caribbean & 120 \\
Developing regions & 37 \\
Least developed countries & 140 \\
World &
\end{tabular}

Source: WHO, UNICEF, UNFPA \& World Bank (2010).
Lifetime Risk of Maternal

Death: 1 in :

One of the countries in the forefront in terms of maternal deaths is Nigeria, which has a significant ratio of maternal mortality in sub-Saharan Africa. Nigeria, which approximately is $2 \%$ of the world's population, has an estimated 59,000 maternal deaths, thereby contributing almost $10 \%$ of the world's maternal deaths (Federal Ministry of Health (FMOH) Nigeria, 2005; Babalola \& Fatusi, 2009). The estimated average maternal mortality ratio in Nigeria is 1,100 for every 100,000, which is higher than the regional average (Hill et al., 2007). However there are variations from one region to another. Maternal mortality is much higher in the North Eastern region of Nigeria, accounting for $75 \%$ of the country's maternal deaths compared to the South East and South West regions (WHO, 2008). Several factors like 
illiteracy and poverty among others contributed immensely to this disparity between the regions. It is evident from the foregoing facts that a critical problem of maternal health still exists in Nigeria and certainly, this issue spreads like wild fire causing devastating effect to developmental progress. By all national and international standards, the high rate of maternal mortality is unacceptable, because it is preventable. Therefore, it is a challenge to the family, the government, and the international community.

Improving maternal health is one of the eight Millennium Development Goals (MDGs) adopted at the 2000 Millennium Summit at the United Nations headquarters in New York. The main focus was to reduce the maternal mortality ratio (MMR) by $75 \%$ between 1990 and 2015. To achieve this aim, many nations across the world have realized the importance of communication as an intervention needed to reduce and prevent maternal deaths and hence improve maternal health (WHO, 2005; Alexander, 2005; Hodgets \& Chamberlain, 2006; Thornson, 2006). Communication is therefore very vital for behavior change to take place because public health programs invariably require behavior change; behavior change cannot occur if the specific target audience is not aware of the message disseminated to them (Alexander, 2005; Thornson, 2006). The fact is that if people are aware of the messages that pose dangers to their health, they might change their bad habits.

\subsection{Statement of the Research Problem}

The under-utilization of Antenatal Care services (ANC) by pregnant women is borne out of the assumption that most of the pregnant women are not adequately exposed to health information from the media (Kistiana, 2009). Research has shown that frequent media exposure, usage and awareness on ANC services can lead to a reduction in maternal mortality (Sood et al., 2009; Kistiana, 2009; Paek, Lee, Salmon, \& Witte, 2008). Several studies (Kistiana, 2009; Sood et al., 2009; Paek, Lee, Salmon, \& Witte, 2008; Ngilangwa, 2007; Keating, Meekers, \& Adewuyi, 2006; Morton \& Duck, 2001; Navaneethan \& Dharmalingam, 2002; Valaente \& Saba, 1998) have confirmed the fact that exposure to the media can lead to greater awareness of health related issues.

Despite the above fact that media exposure leads to greater awareness of health related issues, most pregnant women in Kano state seem not to be adequately exposed to the media for awareness on the importance of utilizing antenatal health services. Even where the women have access to the media, there seem to be insufficient educative programmes on health to make them attend ANC. Several studies have reported that inadequate antenatal care for pregnant women is highly associated with negative ANC consequences and poor results (Raatikainan, Heiskanen, \& Heinonen, 2007). Cox (2009) also found that insufficient antenatal care delivery including communication of health promotion advice among other factors was significantly associated with adverse pregnancy outcomes.

Several factors such as illiteracy and poverty among others tend to limit women's media exposure and usage. Most pregnant women rely only on radio programs that are produced in their local languages and cannot read newspapers or magazines because of a literacy barrier. Kistiana (2009) from a study in Indonesia confirmed that women's education or level of literacy increases their exposure to media information. But in northern Nigeria including Kano, there seem to be high level of illiteracy among pregnant women, which limits their media exposure and usage and because of poverty, even those that are literate do not have 
adequate purchasing power to access information and health services (Ragupathy, 1996). According to his study, Ragupathy's (1996) findings support that being poor limits access to information and health services.

Television as another medium of information requires electricity to operate and in most cases it seems that there is inadequate supply of electricity. For those women who have access to radio, the timing of the radio programs may or may not be suitable for them due to their busy household chores. Again the type of programmes aired on ANC may not be the women's preference. Similarly, the few media programmes on health are not adequately enough to make the women attend ANC. Therefore, all of these factors tend to compound and limit their access, exposure and usage of the media, which consequently will affect their awareness on utilizing antenatal health care services. It is against this background that this study examines the media awareness and usage of pregnant women in the utilization of antenatal health care services in Kano state with a view to finding out their media preferences as well as their major sources of information.

This could assist in the uptake of ANC services and might increase the women's awareness on the need topatronize hospital facilities, which will consequently lead to the decrease of maternal deaths in the society. Therefore, for communication to become effective in preventing maternal deaths, it becomes crucial to understand how individuals and communities perceive and use the information they receive to successfully change their behaviors (Hodgets \&Chamberlain, 2006; Thornson, 2006; Alexander, 2005; WHO, 2005). Similarly, understanding the media preferences of the women and the various factors that influence their preferences will help to develop strategies that will improve utilization of antenatal health services and other maternal health care services, thereby reducing unnecessary loss of lives.

\subsection{Research Questions}

This study is premised on the following research questions:

a. What are the sources of information on antenatal health services by pregnant women in Kano state?

b. What is the media awareness and knowledge on the importance of utilizing antenatal health services by pregnant women in the state?

c. What are the media preferences of pregnant women on antenatal services in the state?

d. What are the factors that hinder the effective utilization of mass media in antenatal services by pregnant women in Kano state?

\subsection{Aim and Objectives of the Study}

The aim of this study is to examine the media awareness and usage in the utilization of antenatal health care services by pregnant women in Kano state.

Specifically, the study has the following objectives:

a. To identify the major sources of information of antenatal health services by pregnant women in Kano state;

b. To determine the media awareness and knowledge of the importance of utilizing antenatal health care services (ANC) by pregnant women in the state; 
c. To determine the media preferences of pregnant women in utilizing ANC services in the state; and

d. To find out the factors that hinders the use of the mass media in ANC services by pregnant women in Kano state.

\subsection{Significance of the Study}

Maternal death is still a global problem that needs to be addressed seriously especially in developing countries where the problem is more pronounced. This study attempts to contribute to the understanding of maternal and reproductive health from the communication perspective. Policy-wise, this work will contribute additional research findings on health communication and promotion, maternal and reproductive health, public health and epidemiology. This research is equally important because of the need to compliment the works of other experts in health and communication fields. The World Health Organization (WHO), the International Planned Parenthood Federation (IPPF), the United Nations Populations Fund (UNFP), the Millennium Developments Goals (MDGs), the West African Media Network (WAMNET) and other various organizations and conferences on reproductive health and women development in the family, are deeply interested in maternal health. The health of the mother is intertwined with that of the child and the whole family and a loss of a mother shatters the whole family and threatens the well-being of surviving children. Generally speaking, there is a need for studies on reproductive and maternal health in the family to better appreciate how to further develop the family institution.

This study will also shed light on the media preferences of pregnant women on ANC programs. There is limited research on assessing the media needs of women. The information from this exploration can enhance the knowledge of media organizations and health care providers working in ANC clinics with the needs of the pregnant women in their voices and this may be unique. Similarly, this study will recommend further research among women, students of communication and health, scholars, research institutes and of course media organizations interested in conducting similar related research on women studies and health communication, which is fast becoming an independent academic field.

\subsection{Literature Review}

Several studies on health in the developing world have revealed the significance of the mass media in spreading messages on health matters (Kistiana, 2009; Hodgets \& Chamberlain, 2006; Thornson, 2006; Alexander, 2005; WHO, 2005). The means of communication normally utilized are the print and the electronic media. Studies have also shown that women's access to mass communication channels contribute immensely to the uptake of health care services (Sood, Sengupta, Shefner-Rogers, \& Palmer, 2009; Kistiana, 2009). Therefore a woman who has access to ANC information is more likely to utilize the service. Navaneethan and Dharmalingam (2002) submit that well-informed women are in a better position to receive ANC services. This shows that exposure to mass media promote health-related behavior in utilizing maternal health services. Therefore, health conscious women may be more likely than other women to initiate ANC early, maintain a regular schedule of visits, and search for prompt medication like birth controls, inter-conception care as well as proper feeding (Walford, Trinh, Wiencrot, \& Lu 2011; Alexandra \& Kotelchuck, 
2001).

Buttressing the above, findings of a study on Impact of SIAGA Campaign on Maternal and Neonatal Communication Knowledge of Danger signs and birth preparedness in West Java, Indonesia revealed that awareness through the channels of mass communication leads to well informed decisions about severe bleeding as a danger sign as well as increased birth preparedness and antenatal behaviors (Sood et al., 2009, Valante \& Saba, 1998). On their path, Valante and Saba (1998) in a study of mass media and interpersonal influence in a reproductive health communication campaign also found that the mass media has a great influence of speeding social change, while Kistiana (2009) in Indonesia found that women's exposure to media had a strong connection to ANC uptake and other maternal health services. In a study on prenatal health promotional needs of immigrant women in Winnipeg, Mugweni (2009) identified lack of knowledge of available resources as the main contributor to nonattendance at ANC clinics. The participants in the study expressed the need for increased awareness of ANC services. This could be achieved through the media. Therefore, comprehensive health promotion through raising awareness using the mass media could help to improve uptake of ANC services (Simkhada et al., 2006). Thus the media perform the necessary functions of providing information that empowers users to action and are an alternative source people rely on for health information about new health risks, disease outbreak and healthy living. The WHO (2005) also recognized that the media both print (newspaper, magazines etc.) and the electronic (radio and TV) have very important roles in driving public opinion and actions to raise their awareness regarding promotion of maternal and child health care. The media have also been recognized as powerful mechanisms to promote the awareness and education of public issues and can probably influence decisions of government and policy makers on health policies and medical care (Evans \& Ulasevich, 2005). Therefore, the mass media play a central role in informing the public about health and medical issues (Thorson, 2006).

Hence, the mass media has the ability to create an informational environment where development is stimulated (WHO, 2005). As Agudosi (2007) maintains, one major way of promoting health care is by engaging in a mass media campaign, which is believed, will reach the target audience and change their behaviors. Deducing from the above one can say that the mass media remains a key component of the global strategy for sustainable health development through adequate information and education on issues of great concern. Thus, in the efforts to decrease maternal mortality, the mass media can continue to play a crucial role of change agent in creating awareness about the importance of utilizing maternal health services like antenatal care.

Most of the literature reviewed were quantitative studies and did not focus on the ANC media experiences from the pregnant women's perspectives. This indicates that there is limited qualitative research to understand the phenomenon under investigation. Confirming this statement, Simkhada et al. (2008) in a systematic review of the literature on the factors affecting the utilization of antenatal care in developing countries, found only four qualitative studies out of the 28 studies included. Twenty-two were quantitative studies. Similarly, Maikaba (2011) also found that the most frequently used methods of conducting research in Mass Communication in Nigerian universities are in the area of quantitative methods 
comprising surveys and content analyses. Therefore, a gap exists.

This study attempted in filling this gap by exploring the pregnant women's experience as the actors involved i.e. exploring actor's own accounts of their experiences rather than simply the outcomes of research utilization. This was in order to enable the pregnant women voices to be heard in terms of their preferred ANC programmes and their most suitable time for the ANC media programmes among others. This detailed information is unavailable in quantitative studies. Armed with the knowledge about the preferences of pregnant women was important in improving their ANC uptake, which would consequently reduce and prevent maternal mortality in the state.

\subsection{Theoretical Framework}

\subsubsection{Health Belief Model}

As a theoretical framework, the health belief model was adopted being one of the models of behavior change typically used for studying and promoting the uptake of health services (Becker, 1974). This model guide and inform health communication and promotion programs as regards to individual response and utilization of health services (Airhihenbuwa \& Obregon, 2006). The health belief Model (HBM) is a psychological model that attempts to explain and predict health behaviors by focusing on the attitudes and beliefs of individuals. The HBM was first developed in the 1950s by social psychologists Houcbaum, Rosenstock and Kegels working in the U.S. Public Health Services. Becker and colleagues furthered HBM in the 1970s and 1980s. Subsequent amendments to the model were made in 1988 to accommodate evolving evidence generated within the health community about the role that knowledge and perceptions play in personal responsibility (Glanz, Rimer, \& Lewis, 2002).

According to this model, the response and utilization of disease prevention programs will be predicated on an individual's perception of the seriousness of the disease, severity of the disease, perceived benefit of services, and barriers to accessing such services (Janz \& Becker, 1984; Strecher \& Rosenstock, 1997). Glanz, Rimer, \& Lewis (2002) stated that more recently, HBM has been amended to include the notion of self-efficacy or one's confidence in the ability to successfully perform an action or the desired behavior. Similarly, the scholars argued that a wide variety of demographic, social, psychological, and structural variables might also impact people's perceptions and, indirectly, their health-related behaviors. These mediating factors were later added to the HBM to connect the various types of perceptions with the predicted health behavior. Some of the more important variables include educational attainment, age, gender, socioeconomic status, personality and prior knowledge to mention just a few. The Health Belief Model is depicted in Figure 1 below: 


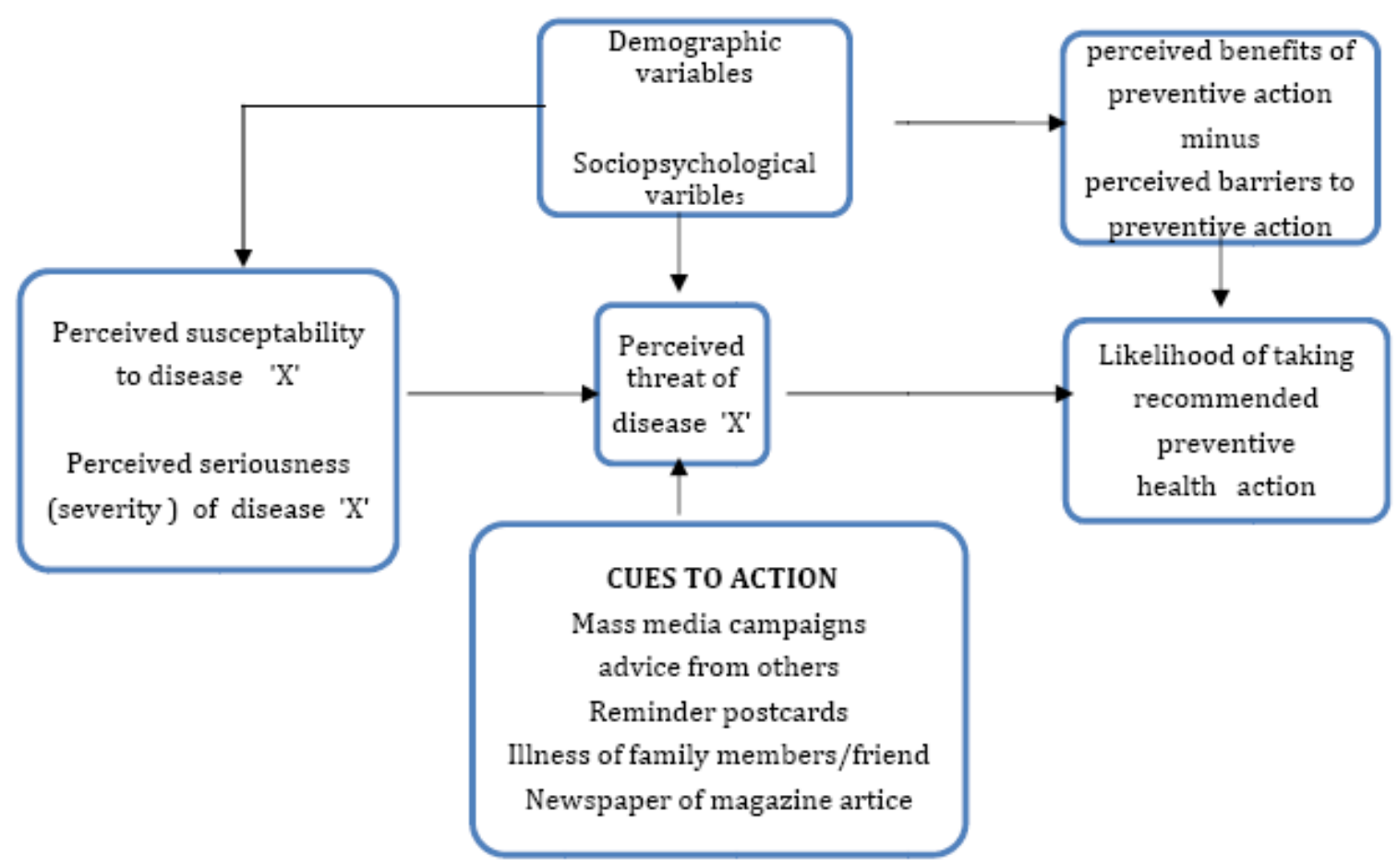

Figure 1. The Health Belief Model

Source: Adopted and modified from Glance et al, 2002.

\subsubsection{Development Media Theory}

The concept of maternal health and antenatal care is also anchored on development media theory. Development Media Theory attempts to explain the role of the press in fostering development and it looks at the press in countries that are conventionally classified as developing countries or third world. The theory lies on the use of the media positively to promote the much needed development and transformation in the society (McQuail, 2005). The Development Media Theory is used in this study because maternal health (i.e. antenatal care) is a development issue, therefore through communication women could be brought into the process of identifying their needs of maternal and reproductive health for sustainable development in the society. This implies the need for an increased awareness of maternal health issues by the media and other information organizations.

\subsubsection{Systems Theory}

The Systems theory is also relevant to this study. As Parsons (1960) states that all social systems have certain basic needs, which must be met if they are to survive. These needs are known as functional prerequisites namely; adaptation to the environment, goal attainment and integration of units into the larger social system and maintenance of value patterns over time. Thus, the function of any part of society is its contribution to the maintenance of the society 
(Parson, 1960). This means that the major parts of an organization must work harmoniously for the survival of the organization in particular and the social system in general. The family is the core sub unit of the social system and the mother and the child are the main constituents of the social system. The health of the mother is intertwined with that of the child and the whole family and the loss of a mother shatters the whole family and threatens the well-being of surviving children and her contribution to the development of her society is wasted.Although, the above theories have been utilized in this research, there are other theories that are equally relevant including the Uses and Gratification theory and the Risk Reduction Management theory.

\subsection{Scope and Limitations}

Location, time, study sample, focus, study design and the theoretical framework bound this study. The North West zone of Nigeria, which comprises seven states Kano inclusive, has the second highest rate of maternal mortality after the North East (WHO, 2007). Kano State has the highest incidence of maternal deaths in the zone (WHO, 2008) and hence represents a model on ways to reduce maternal deaths of recent. The study took place only in five selected health institutions in Kano state in the year 2011. Purposive sampling used in this study permits researchers to connect the purpose of their studies directly to their sampling strategy. As Patton (2002) contends that the logic and power of purposive sampling lies in selecting information-rich cases for in-depth study. The scholar stressed, "information-rich cases are those from which one can learn a great deal about issues of central importance to the purpose of inquiry" (Patton, 2002, p. 230).

The five health institutions purposively selected were: Murtala Mohammed Specialist Hospital (MMSH), Aminu Kano Teaching Hospital (AKTH), Mohammadu Abdullahi Wase Specialist Hospital (MAWSH), Sheik Mohammed Jidda General Hospital (SMJGH) and Sir Mohammad Sunusi General Hospital (SMSGH). The selection of these health institutions were based on the fact that majority of pregnant women from all the 44 local governments of Kano state including neighboring states patronize these hospitals and even those in the rural areas get referrals to access antenatal services from these health institutions. In addition, the health institutions were also chosen because they could provide the required population and the data needed for the study.

This study sample consisted of 115 participants i.e. 100 pregnant women, 10 health workers and 5 media personnel. The pregnant women were between the reproductive years of 15-49 who presented themselves for ANC services in the selected public Health institutions in Kano state. This age limit was chosen based on the reference by the Society of Gynecology of Nigeria in 1986 that ages of between 15-49 years are the reproductive ages. Similarly, this age category is more prone to the risk of maternal mortality especially because of lack of ANC. Therefore pregnant women who did not fall under this age category and do not attend these health institutions were excluded from the study.

The study focused on eliciting their media usage, knowledge and awareness on utilizing ANC services. The health workers and media personnel formed the other category of participants termed the significant others. The rationale for including the significant others was based on their expertise and experience as well as their direct role in promoting the utilization of ANC services for pregnant women in the state. This category of participants are important for data 
triangulation purposes as they will assist in providing a holistic picture of the issues under investigation as well as provide thick and rich description of the phenomenon. Therefore, their views and experience on ANC were very important and fulfills the information rich criterion.

One limitation of this study is that the selected health institutions may not represent the entire population of health institutions in Kano state. Therefore, scientific generalizations of the findings of the study may prove difficult. In the same vein the study was only conducted in government health institutions as such private health institutions were excluded from the study.Secondly, the study did not apply to the general population of women in Kano state. The study only included the experiences of pregnant women in the selected health institutions and hence provided an in-depth and thick description of their media usage and awareness in the utilization of ANC services. This rich and thick data description provided in-depth understanding of the phenomenon under investigation, which could be informative, instructive and sometimes transferable to other settings (Jensen, 2012; Berg, 2009).

\section{Methodology}

This study utilized qualitative method in order to generate unstructured data from contextual reality by the understanding of everyday life of the members performing the actions (i.e. obtaining facts from practical experiences of the pregnant women). In addition, based on the research questions and the interview guide required in this research project, qualitative methodology is adopted. Jensen (2012), Lindolf and Taylor, (2011) and Patton (2002) asserted that research questions have the power to dictate the best research design in order to elicit the best answers. Therefore, the nature of the research understanding the media awareness and usage of ANC services by pregnant women in Kano state have exposed the women's experiences and realities embarked upon under the qualitative study. It is only qualitative inquiry, which examines people's realities as a phenomenon under study (Hartley, 2011).

Qualitative method is defined as a technique of knowledge generation through face-to-face contact between the researcher and the subject of research (Jensen, 2012; Lindolf \& Taylor, 2011; Berg, 2009). According to Gunter (2000) the qualitative method is a critical interpretative approach because it is more concerned with interpretation "and understanding of how people interact with and make sense of the media through reference to various communities which represent membership or reference groups from which they derive their values and standards" (p. 22). These things can be difficult to quantify and may be better understood through qualitative methodologies. Similarly, Jensen (2012) stated that a common feature of qualitative studies is the conception of researchers as interpretive subjects and the pervasive nature of interpretation throughout the research process.

The researcher's major data collection methods were Focus Group Discussion (FGD), In-depth Interviews (IDIs) and Document Analysis. The rationale of using these methods was to physically meet and talk to the participants, observing them and their environment as well as analyzing documents for as many layers of data as possible. As Patton (2002) rightly observed that qualitative findings grow out of three kinds of data collection: in-depth, open-ended interviews; direct observation; and written documents. These varied methods were important to this study for triangulation purposes and specifically, the IDIs and FGDs 
generated direct quotes indicating participants' knowledge, opinions, beliefs, feelings and experiences. This study used the three data collection methods of FGD, IDI and Documents which were useful in gathering data from the participants to understand media awareness, usage and knowledge in the utilization of ANC services by pregnant women in Kano state, thereby enabling a thick and rich description of the phenomenon under study.

Focus group discussion (FGD) was employed at the first stage of the study and was conducted with pregnant women to elicit responses based on their personal views, knowledge and experiences. FGD encourages interviewing several participants together in a semi-structured discussion on a selected topic in order to elicit data based on their ideas, opinions and feelings (Gunter, 2000; Kruegar \& Casey, 2000). According to Wimmer and Dominick (2011) focus group or group interviewing is a method of generating qualitative data for understanding the behavior and attitude of respondents. Data from focus groups are very informative and reflective of real life situations used to enhance understanding of everyday life, collect more information and to reveal a wide range of opinions, some of which the researcher might not expect (Umar, 2006). In essence, FGD enables a researcher to gain insights into people's shared understandings of everyday life and the ways in which others influence individuals in a group situation (Dlakwa, 2006).

In-depth interview (IDI) was adopted to complement the FGD method at the second stage of the study. IDIs were conducted with key informants of the health workers (i.e. doctors, nurses and midwives) and media personnel and managers. The interviews with the health workers provided more detailed information on ANC services and revealed the general situation of ANC utilization by pregnant women in Kano state. On the other hand, the IDIs conducted with the media personnel and managers revealed the kind of programs that were produced and broadcasted in the media outfits in relation to maternal and antenatal health. These types of programs were believed to have the capabilities of influencing women to utilize ANC services.

In-depth or unstructured interviews are probably the most widely and main methods of data collection used in qualitative research (Ritchie, 2003). They take different forms but a key feature is their ability to provide an undiluted focus on the individual. Ritchie (2003) confirms that individual interviews provide an opportunity for detailed investigation of people's personal perspectives, for in-depth understanding of the personal context within which the research phenomena are located, and for very detailed subject coverage. Legard, Keegan and Ward (2003) further stated that IDIs are also particularly well suited to research that requires an understanding of deeply rooted or delicate phenomena or responses to complex systems, processes or experiences because of the depth of focus and the opportunity they offer for clarification and detailed understanding.

In this study, the researcher also used some documents for analysis. They include data from the planning department and ANC attendance registers from the health institutions, data obtained from state health management information system-Kano State Ministry of Health, data from Kano state National Population Commission, data from AKTH, Community Medicine department and program schedules of the media organizations. These documents provided insights into the perspectives, assumptions, concerns and activities of the ANC services. ANC records assisted the researcher in knowing the attendance rate of the pregnant 
women. By analyzing the documents, the researcher corroborated what was observed and the claims made by the interviewees. The program schedules assisted in finding out the frequencies of the ANC programs.

Relevant documents are is also critical sources of data in qualitative research. Documentary analysis involves the study of existing documents, either to understand their substantive content or to illuminate deeper meanings, which may be revealed by their style and coverage (Ritchie, 2003). These may be "public documents like media reports, government papers or publicity materials; procedural documents like minutes of meetings, formal letters or financial accounts; or personal documents like diaries, letters or photographs " (Ritchie, 2003. p. 35). Similarly, Patton (2002) stated that documents vary from "studying excerpts, quotation, or entire passages from organizational, clinical, or program records; memoranda and correspondence; official publications and reports; personal diaries; open-ended written responses and survey" (p. 4). Therefore, documents constitute a particularly rich source of information and they give a clear setting of the time when the document was formed.

Furthermore, Babbie (2001) stressed that documentary analysis is particularly useful where history of events or experiences has relevance. According to Glesne (2006), document analysis deepens people's understanding from interviews and observation. In addition, they help the researcher to learn other aspects to develop in the study. In fact, May (2001) argues that documents reinforce the credibility of the study findings, reinforcing the importance of doing a document analysis. Documents analysis are done to support data collection techniques used and to shape the study direction.

The data collected or generated for this study were mainly textual derived from the transcriptions and notes taken during the sessions for both the focus groups and the in-depth interviews. The data generated were coded and analyzed using thematic approach i.e. organized under various key headings to enable the classifications of views. Furthermore, the data were illustrated by quotes directly from participants as explained by Gunter (2000).

\section{Major Findings/Themes of the Study}

This section presents the major findings of the four questions arranged by the emerging themes.

\subsection{Findings of Research Question One (RQ 1): Sources of Information on ANC}

On the pregnant women's major sources of information on ANC services, the data revealed a wide range of information sources available to the women. However the media (particularly, radio) was their main source of accessing information for ANC. Radio stations like Freedom Radio, Radio Kano, Pyramid FM, and other foreign radio stations like BBC and Duetshwelle were their major channels. According to a participant from $\mathrm{CHCK}$ :

Sincerely speaking we get most information from radio because not all people have Television, and gatherings, it is not all women that attend gatherings and hear these pieces of information, but radio when you switch it on even if there are more than ten people beside the radio, all of them will hear the information.

Findings of Paek et al. (2008) found that exposure to health related radio programs were a significant predictor of family planning and other maternal health services. Therefore radio remained the most accessible source of information concerning antenatal health as well as 
other maternal and reproductive health (NARHS, 2005). Other sources available to the pregnant women were health workers (hospitals), neighbors and friends, community leaders and social gatherings among others. These sources and the information acquired to a large extent influenced the utilization of ANC services by the pregnant women. Based on the data therefore, the researcher concluded that the more of such sources available, the higher the utilization of the ANC services among pregnant women in Kano state. Similarly, the more pregnant women obtained information on ANC, the higher the use of the ANC services. Therefore, the media, hospital, social gatherings etc. have played a vital role in mobilizing pregnant women towards the utilization of ANC and other maternal health services.

\subsubsection{RQ2: Media Awareness and Knowledge of ANC programs}

There was good awareness and knowledge of the importance of utilizing ANC among the respondents. Findings on awareness revealed that majority of the pregnant women were aware of the need to attend ANC services. For instance all the participants of the two FGDs conducted at Sharada clinic (PHCS) testified to the fact that pregnant women were aware of the ANC services. According to a discussant:

Women are aware and I think this is where we are now, there is progress because women are now enlightened and they attend ANC. Women are aware of the campaign for ANC and are informed because if you visit ANC clinics you will see a large turnout of women.

In a KII, aphysician supported the above statement:

Well the antenatal clinics in Kano state I can say there is a general increase in the attendance of antenatal among women. This may be associated with some factors such as increase in the level of knowledge, awareness of the problems associated with delivery at home and pregnancy-associated problems. So women tend to come for antenatal.

Although the data revealed that most women are aware of the need to attend ANC services, several reasons have been put forward by the participants why pregnant women do not attend ANC clinics despite their awareness. Some of the reasons were women's stubbornness, husband's refusal, health workers attitude, long waiting periods, belief in pre-destination, poverty, distance etc.

i. This study found that due to stubbornness, some women refuse to attend ANC in spite of the fact that they were fully aware. Participant four from PHCS:

Women are really aware and they normally hear every day there is a campaign on health messages on ANC attending because of the complications involved, but due to stubbornness, women just stay away and refuse to go to the hospital for ANC. Some even say that they are healthy then what will they do in the hospital.

ii. Related to the issue of stubbornness is laziness. Laziness was identified in the study as another reason why pregnant women do not attend ANC despite being aware. Participant one from SMSGH narrated that:

Some women are lazy and feel that they cannot walk from the house and come to the hospital. This makes them not to attend while others say they have a lot of work to do in the house that they cannot come to the hospital.

In line with the above therefore, the study found that some women were accused of being lazy and don't attend ANC despite their awareness. 
iii. The study also found that Health workers attitudewas another main reason why pregnant women do not want to attend ANC despite their awareness. Large number of the pregnant women that participated in this study admits that the attitude of health workers is not encouraging at all and hence does not motivate the women to attend ANC. A participant at SMSGH revealed that:

To be candid some women like to come for ANC but they are afraid of the attitude of the health workers who shout and treat them in a hostile manner. That is why some say let them stay at home and use traditional means and then refuse to attend the clinics for the ANC.

Similarly, another respondent from MAWSH confirmed the statement:

Health workers should stop shouting or abusing the pregnant women. You see this is not good it even make a woman not to attend.

From the above mentioned therefore, the negative attitude of health care providers often described as rude, unfriendly and hostile discouraged some pregnant women in accessing ANC. For instance, studies by Adamu and Salihu (2002), Fatusi and Ijadunola (2003), Abdullahi (2004), Sabitu (2004), Alubo (2004), Adamu (2006) and Dalhatu (2006) also observed the unfriendly, hostile and rude attitude of healthcare providers, particularly nurses and midwives.

iv. Related to the above finding is the issue of long waiting periods in these ANC clinics, which also prevents the pregnant women from attending ANC despite the fact that they are aware of its importance. The study found out that staying for longer periods at the clinic before being attended to, was another reason which pushes the women off and don't want to attend the ANC clinics. A participant at SMJGH narrated:

If the pregnant women attend once they don't normally come back, the women normally say that if they attend once when they come back again it is not likely for them to receive the ANC on time.

This finding corroborates an assertion made by a physician that most of the pregnant women think of ANC as a stress because of coming to the hospital and waiting for longer hours before they are finally seen, may be in the late afternoon hours. Therefore, some of the pregnant women cannot wait or stay for longer time at the clinics and this distracts them from attending ANC, they cannot wait.

v. The study also found that Belief in Pre-destination was another strong factor that prevented pregnant women from attending ANC services despite their awareness. Among the respondents there were those who strongly believed in pre-destination, meaning that whatever happened to them was the will of God. A participant at PHCS stated that:

Yes this is the fact, although they are aware some say that it is not necessary for me to attend the hospital, that giving birth is in the hands of Allah and He will deliver me safely.

Belief in pre destination was therefore still a very strong force as Adamu (2010) found that people have fatalistic attitudes towards pregnancy and childbirth, as a result, complications (that can lead to death or disability) are seen as a natural phenomenon or the will of God as such cannot be interfered with.

vi. Another major important finding related to awareness was the issue that some women are aware but their husbands and in-laws do not allow them to attend ANC. Almost all the 
women $(99 \%)$ believed that husband, mother and father in- laws as well as other older family members in the household contributed immensely to their non-attendance to ANC services despite the fact that they are quite aware of the importance. A participant from MAWSH stated that:

What I want to say is that most of the problems are from husbands. For instance it was from the radio I heard a woman crying that she was pregnant but her husband and her mother in-law refuse to let her attend ANC. Most of the problems are from men and when childbirth comes it is the woman who suffers not the men.

This finding revealed that pregnant women even though they might be aware and want to attend ANC, if their husbands or in-laws denied them the right to attend, there is no way they could benefit from such services. Married women in Hausa communities are not allowed to go out unless they seek permission from their husbands and if the husbands are not around, the power rests in the hands of the father or mother in-law (Adamu, 2010; Mohammed, 2005; UNFPA, 2001).

vii. An important finding from the study revealed that one of the reasons for the husband's refusal to let their wives attend ANC is economic problem. Some husbands do not have sufficient money to pay for the hospital bills so they cover up, and pretend that they do not want the women to attend ANC. This was disclosed by the assistant nursing/midwife officer in-charge of ANC at MMSH that: "sometimes it is the husbands who have the problem. They don't have the money to give their wives to come to the hospital." (Nurse, IDI, December 2011). Therefore, the declining incomes and low purchasing power coupled with high cost of drugs and treatment have combined to keep health services out of reach of many pregnant women (Singh et al., 2012; Iliyasu et al., 2010; Adamu, 2010; Brugha, Brown \&Alihonou, 2003; Abdullahi \& Mahmud, 2003; Abdullahi, 2004; Sabitu, 2004).

viii. The final but very important theme that emerged under the awareness issue is the fact that some women were not even aware at all, of the importance to seek antenatal care. The study found that some pregnant women even in the urban areas are not aware about ANC due to lack of education, talk less of those leaving in the rural areas. Participant six at SMSGH revealed, "Some pregnant women don't know about ANC and that is why they do not attend, especially our women in the rural areas are not aware" (p. 6, FGD, December 2011). This finding concurs with that of a physician:

Well many of them, many of them particularly in the rural areas are not aware. In the urban areas fine many of them are aware they come even though they may end up not delivering in the hospital yes, but in the rural areas I think many of them are not aware and then compounded with poverty, to even access health services to transport themselves to the health facilities is difficult.

The data indicate that lack of education was a factor leading to lack of awareness of some pregnant women about ANC services. A respondent submitted that "some are not aware because they are less educated, they don't know its importance and benefits, and they don't want to attend ANC because they don't know its uses" (p. 1, FGD at MMSH, December, 2011). This finding was supported by a revelation by a medical doctor:

I think ANC service utilization depends on the educational status of women especially in this 
community. Initially the more educated women tend to search for antenatal care while the less educated ones remain at home, they never even attend a single antenatal care before delivery and they will deliver at home, they will manage their children, and funny enough some of them don't turn out to have problems.

Therefore, women's education or level of literacy has a significant relationship with the utilization of antenatal care and modern delivery care (Kistiana, 2009; Sood et al., 2009; Paek, Lee, Salmon, 2008).

\section{3 RQ3: Media Preferences of Pregnant Women in Kano State}

i. The study found that almost $99 \%$ of the pregnant women chose radio as their most preferred medium for accessing information on ANC. According to the participants this was because radio is universal, portable, cheaper, and easier to communicate and a bunch of other reasons. A participant from MMSH explained that:

Radio we mostly hear and use because it is universal and everybody has it. Everywhere you can hear it. Even if you don't have TV you can buy batteries and listen, even a Fulani herdsman in the bush can tune his radio. So it is easier for everybody, both the rich and poor.

A medical doctor also agreed that:

In the northern part of Nigeria and Kano in particular people listen to radio more than any other forms of communication be it newspaper, be it a TV or any other method of information. So radio in fact I can give good example if you say 80 to $90 \%$ of Kano people listen to Freedom Radio and other related radios, I know this statistics will be right, so I think radio will be the main medium of communication.

ii. The study also found that other participants also submitted that they listened to the radio all the time from morning till evening because no electricity was involved and radio created more awareness especially to the rural dwellers. Therefore radio remained the best medium for disseminating information on ANC for both men and women for reaching a larger audience.

iii. In connection with the most preferred ANC media program, the study found that majority of the respondents' preferred ANC programs in which Medical experts (i.e. doctors) were invited over the media (radio preferable) to give a discussion on maternal health problems and issues. A participant narrated:

We prefer a radio program in which they invite a medical doctor to discuss and shed more light. If you listen to it you will benefit a lot from such programs because you will hear them talking about some problems that is disturbing you or your children or even somebody who is related to you. Therefore if a woman listens to such programs she gets convinced and visits the ANC clinics.

iv. According to the findings, the participants preferred such programs with medical experts because they belief such discussions captured more of their attention and were more appealing to the pregnant women. These experts encouraged and supported them to attend ANC with their detailed explanations, which were research based, and not mere speculations, according to the participants. They also believed that such programs went a long way in convincing even their husbands to allow them attend ANC. In these programs feedback was also possible through interactions using cell phones. 
$\mathrm{v}$. The study also found out that $4.00 \mathrm{pm}$ towards the night was the most appropriate time for pregnant women to listen to such programs. This was because by that time they have completed all their house chores and could listen attentively to such programs. Men could also be captured to listen at night when they are back from work.

vi. Additionally, this study found that ANC media messages impacted on the pregnant women. According to the participants ANC programs were very effective in changing a woman's behavior as well as encouraging her to attend the clinics. A discussant noted, "It is capable of changing a woman's behavior because the messages are like warning messages or even counseling, if a person hears then he becomes aware or alert and this counseling makes him to attend the ANC clinics."

vii. Other participants submitted that the programs also have the capability of convincing the husbands to allow their wives to attend ANC. The respondents added that these media messages in which medical experts were invited on radios, served as a warning alert, making them conscious of life realities in order to avoid any complications. The programs further make women to adopt healthy and clean living habits especially when explained carefully in a polite and convincing manner.

\subsection{RQ4: Challenges of Pregnant Women in the use of the Media for ANC}

Generally, findings that emerged from the field data indicate that there are a number of factors that hinder the use of the media for accessing ANC services by the pregnant women. The major problems were mainly lack of access to the media, economic problems, power failures, low feedback and inappropriate broadcast timing.

i. The study found that due to poverty, lack of occupation and economic power, some of the pregnant women do not have access to the media where they could listen to the ANC programs especially those living in the rural areas. A participant submitted that, "Sincerely speaking women are facing a lot of problems especially if you do not have the radio, or TV and you are leaving in the rural area or if your batteries are weak when the program is aired and you do not have the money to buy them. To be candid even in cities there are some women who do not have a radio in their own house. So even if somebody advice you, you will be wondering is the thing true or false.

ii. Some of the participants complained that they do not have any economic activity that will fetch them money to buy batteries in order to listen to such ANC programs. Some times their radio is even damaged and it takes long to get it repaired because of lack of money.

iii. Power failure due to lack of electricity was another challenge to the pregnant women. According to participants if you are using a medium of communication that requires the use of electricity like TV or an electric radio, you will be frustrated because all the time there is power failure. A respondent revealed that:

Women are facing a lot of problems especially power failure, when there is no light, and you are using a TV or electric radio, you cannot see or hear the ANC programs when aired, so women are frustrated especially if the story is narrated to them later about the programs, you feel bad.

iv. Additionally, lack of feedback when the ANC programs are on air, was another obstacle that affects the pregnant women. According to the participants, lack of interaction through 
feedback between them and the presenters of the ANC programs was also not encouraging. Some of the ANC programs are one way and do not provide room for interaction while on the other hand some women do not have cell phones to make calls during the interactive programs. According to a discussant:

Sometimes in the program we will hear people making use of their cell phones to call and ask questions, you feel like also calling at your home, but you cannot, so you can only listen to the program like that and you cannot ask questions.

$\mathrm{v}$. Another challenge discovered from the findings of this study was the inappropriate timing of the broadcast of the ANC programs. According to the participants, the programs are aired when the pregnant women are not at home to listen or when they are not composed enough to listen attentively. A respondent posits, "When the program is aired and the person has to go out to do other things". Therefore, all of the above factors and many others serve as a form of hindrance to the pregnant women in Kano state in the successful use of the media for ANC programs.

\section{Implications}

\subsection{Husbands}

A striking finding in this study is the revelation that pregnant women even though aware of the benefits and importance of ANC and other reproductive health services, when their husbands deny them the right to attend, there is no way they could benefit from such services. This implies the unequal status of women in the Hausa society because men in particular husbands make all decisions including going to the hospital for ANC. This is a very serious implication in that access to reproductive services such as antenatal care or family planning depends on the husband's consent and where such consent is withheld, the woman has no choice but to submit.

In a predominantly Hausa/Fulani community like Kano state most women are guarded and guided by the doctrines of Islamic religion where men particularly husbands make all the decisions including reproductive services. This strengthens the assertion that the Hausa society located in Northern part of Nigeria is patriarchy with strong male influence on many household decisions (Mohammed, 2005; UNFPA, 2001). Therefore, for ANC media messages to be effective and make strong impact, it must target husbands and in-laws since they make the decisions. Similarly, law should be enacted that will enable women to seek for their health and hence make them more empowered.

\subsection{Social Gatherings}

Findings from the study reveal that pregnant women get some of the information on ANC at social gatherings like naming ceremonies and weddings. This implies the significance of social gatherings and friends as strong force in affecting people and changing their predispositions about issues. Most Hausa women like to attend weddings especially, and even in the rural areas weddings are very important social gathering for most women to attend. Therefore interpersonal communication could be employed to target social events and disseminate ANC messages to the women.

\subsection{Community/Religious Leaders, Schools, Health Campaign Messages}

The study found out that the above are also sources through which pregnant women get some 
of the information on ANC. This implies the importance of these sources in dissemination of information. Therefore, ANC messages should target community and religious leaders because people respect and have confidence in them. As such they could be used to spread health messages strategically to the people. Similarly schools are important socializing agent that could as well be used for such purposes. In the same vein health campaign messages from ministry of health could also focus on the importance of utilizing ANC for pregnant women and disseminate health campaign messages at strategic places.

\subsection{Women's Awareness of the ANC servicesyet not attending}

Findings from the study reveal that some women do not attend ANC despite their awareness. This implies that the women are still ignorant of the benefits of ANC. Therefore the finding suggests the need for more intensive enlightenment of health campaign messages especially through the media to reach this group of women.

\subsection{Women's Laziness in attending ANC despite Awareness}

The above finding implies that some ANC clinics are located far away from some communities and the distance makes the women unable to attend. There is a need for providing more ANC clinics near each community. Similarly this finding signifies low economic power of these women because even though if the ANC services are not near the communities, when the women or their husbands are economically empowered, they can still access these services. This further suggests the need to empower women to be self-reliant.

\subsection{Health Workers Attitude}

The implication here is that the unfriendly attitude of the health workers discourages the pregnant women to visit the clinics and also make them to lose faith in the ANC utilization of the modern medical services. The women may resort to continue patronizing the traditional sources who they belief are more available and the operators more courteous. This important finding suggest a need for re-orientation and re-training of health workers especially the nurses and midwives on the right and proper manner of approach in dealing with these pregnant women in terms of human relations. Interpersonal communication is very effective in capturing people's mind. Health workers need to know that their patients need to be handled politely and even pampered so that they can enjoy coming to the clinics instead of being discouraged. This is an important issue for the policy makers.

\subsection{Long Waiting Time as a Reason of Not Wanting to Attend ANC}

The study found out that some of the pregnant women do not want to attend ANC clinics because of the long waiting periods before the health workers attend to them. This implies that the health workers are not adequately enough to give the ANC services. The finding suggest the need to recruit more qualified health workers in order to reduce the work burden and amount of waiting time spent at the ANC clinics by these pregnant women. This is another important policy issue for the stakeholders involved.

\section{Conclusion}

This study was conducted in some selected health institutions of Kano state with a view to examine the media awareness, usage and knowledge in the utilization of antenatal health care services by pregnant women. Findings from the FGDs, IDIs, and facility data clearly indicate that some women still do not attend ANC services despite being aware. The main issue of this 
study revealed that pregnant women even though aware of the benefits and importance of ANC and other reproductive services, when their husbands deny them the right to attend, there is no way they could benefit from such services. When such consent is withheld, the woman has no choice. As per utilization of ANC services and facilities, this study concludes, that though there is knowledge on ANC benefits and high level of awareness, yet the utilization is nothing to write home about. Considering the fact that Kano state is one of the most populated states in Nigeria, but only a small percentage of the women attend ANC services.

Findings of this study revealed that socio-economic factors were the major determinants of ANC utilization. The unequal status of women in the society because men, particularly husbands, make all decisions including going to the hospital for ANC and other reproductive services as well as the negative attitude of health workers have combined to pose a bottleneck to ANC utilization. Similarly, poverty is equally an important factor in that seeking ANC involves a series of cash demanding procedure, from deciding to seek the care, transportation, to payment of other medical bills. Therefore economic constraint or financial closure have prevented many pregnant women from utilizing ANC services even when the need arise. And all these factors may be responsible for high maternal mortality in the state.

\section{Recommendations}

Based on the findings of this research, the following recommendations are offered to improve media awareness, knowledge, and usage of utilizing Antenatal health services by pregnant women in Kano state of northern Nigeria. The recommendations are presented thematically:

\subsection{Media Organizations}

- All media ANC messages should target men as partners in progress in matters related to maternal health.

- Media men and health workers should target social gatherings for the dissemination of ANC messages especially through interpersonal communication.

- The media should produce more quality programs on women's health especially ANC and other maternal health programs.

- The media should inform pregnant women of the incentives given to those who attend ANC because this encourages other women to attend.

- Media houses should produce programs that will educate the health workers especially the nurses and the midwives on human relations.

\subsection{Government/Wealthy Individuals/NGOs}

- Government should provide free readily available drugs and ANC services to pregnant women to enable them attend clinics.

- Government should provide job opportunities in particular vocational training that will equip people in rural communities with source of earning a decent living.

- Government should enact a law that would permit women to seek for their own health as well as recruit more trained health workers that would give effective ANC services to the pregnant women. 
- Since education is a powerful factor towards positive attitude to health care system including ANC, government should commit itself towards Universal Basic Education scheme with a view to ensure access to basic education for all.

- Government should establish more ANC clinics close to each community.

6.3 Health Administrators/Managers and Health Workers

- The health administrators or managers should sensitize the health personnel more especially in the areas of service delivery and attitude in order to improve their communication skills.

\subsection{Husbands}

- Husbands should permit their wives to access and use ANC services. They should give them all the necessary support and encouragement for them to attend.

\subsection{Religious/Community Leaders}

- Within the context of Muslim societies especially in the north here, the mosques are very important vehicles that should be used as agent of change.

\subsection{Pregnant Women}

- The pregnant women should be attending ANC for positive pregnancy outcomeswith respect to both their health and their babies'.

\section{References}

Abdullahi, S. (2004). Socio-Cultural Context of Reproductive Health and Gender issues in Katsina State. Report submitted to UNFPA, Nigeria.

Abdullahi, S. A., \& Mahmoud, M. N. (2003). Baseline Survey on Sustainable Maternal Health Care Behavior: Improvement Initiative conducted in Minjibir LGA, Kano State, Lagos: Pathfinder International.

Adamu, Y. M., \& Salihu, H. M. (2002). Barrier to use of Antenatal and Obstetric Care Services in rural Kano, Nigerian. Journal of Obstetrics \& Gynaecology, 22(6), 600-603,

Adamu, Y. M. (2005). Patterns of Maternal Mortality and Morbidity in Kano State. A Geographical Analysis. Journal of Social and Management Sciences, 9, 196-221.

Adamu, Y. M. (2006). Attractions and Barriers to the use of Antenatal and Obstetric Care Services in Urban Kano. Nigerian Journal of Obstetric and Gynecology, 26(8), 300-304.

Adamu, Y. M. (2010) Maternal Mortality in Nigeria: Acase Study of Kano State Germany: VDM, Moller.

Agudusi, F. (2007). "Mass Media and the promotion of Health care in Rura Communities" in Ebenezar Soola Communication Conference Proceedings.

Airhihenbuwa, C. O., \& Obregon, R. (2006). A Critical Assessment of Theories/Models used in Health Communication for HIV/AIDS. In A. Gumucio-Dagron, \& T. Tufle, (Ed.), Communication for Social Change Anthology: Historical and Contemporary Readings, USA: Communication for Social Change Consortium, Inc. 
Alexander, G. R., \& Kotelchuck, M. (2001). Assessing the Role and Effectiveness of Prenatal Care: History, Challenges and Directions for Future Research. Public Health Reproduction, 116(4), 306-10.

Alexander, S. (2005). The Role of the Media in Attaining the MDGs. Development, 48, 129-131.

Alubo, S. O. (2004). Socio-Cultrual Context of Reprodutive Health and Gener issues in Nassarawa State. Report submitted to UNFPA, Nigeria.

Babbie, E. (2001). The Practice of Social Research. California: Wadsworth Learning.

Babalola, S., \& Fatusi, A. (2009). Determinants of Use of Maternal Health Services in Nigeria: Looking Beyond Individual and Household factors. BMC Pregnancy Childbirth, $9(43)$.

BBC News. (2003). "Nigeria's Economy Dominated by oil”, Retrived from www.pubmedcentral.nih.gov

Becker, M. H. (1974). The Health Belief Model and Personal Health Behaviours. Health Education Monographs, 2, 324-508.

Berg, B. L. (2009). Qualitative Research Methods for Social Science (7th ed.). Boston: Ally \& Bacon.

Brugha, R, Brown, E, \& Alihonou, E. (2003). Costs of Near-Miss Obstetric Complications for Women and their Families in Benin \& Ghana. Health Policy and Planning, 18(4), 383-392.

Creswell, J. W. (2001). Qualitative Inquiry and Research Design: Choosing among the Five Approaches (2nd ed.). Thousands Oaks, CA: Sage.

Cox, S. M. (2009). Prenatal Care Experience and Infant Health outcomes among low-income in Eight states, 1996-2003. PhD Dissertation, University of Illonois, Chicago.

Dalhatu, S. (2006). A formative Assessment Report of Emergency Obstetric and Maternal New born care (EMONC) in Kano and Zamfara States. Submitted to ACCESS/USAID Abuja-Nigeria.

Delva, W., Yard, E., Luchters, S., Chersich, M. F., Muigai, E., Oyier, V., \& Temmerman, M. (2010). A Safe Motherhood Project in Kenya: Assessment of Antenatal Attendance, Service Provision and Implications for PMTCT. Tropical Medicine and international Health, 15(5), 584-591.

Dlakwa, H. D. (2006). Qualitative Research for Development. In Y. M. Adamu, H. Mohammed \& K. I. Dandago (Eds.). Readings in Social Science Research. (pp. 39-49). Kano: Adamu Joji Publishers.

Evans, W., \& Ulasevich, A. (2005). News Media tackling of Tobacco control: A Review of sampling methodologies, Journal of Health Communication, 10, 403-417. 
Federal Ministry of Health. (2006). National Health Promotion Policy.Nigeria: Paths, DFID, WHO.

Fatusi, A., \& Ijadunola, K. T. (2003). National Study on Essential Obstetric Facilities in Nigeria, Federal Ministry of Health Nigeria.

Federal Ministry of Health. (2007). Integrated Maternal, Newborn andChild Health strategy.

Glanz, K, Rimer, B. K., \& Lewis, F. M. (2002). Health Behaviour and HealthEducation Theory, Research and Practice, San Francisco: Willey \& Sons.

Glesne, C. (2006). Becoming Qualitative Researchers: An introduction (3rd ed.). Boston: Pearson Education.

Gunter, B. (2000). Media Research Methods, London: Sage Publications.

Hartley, J. (2011). Communication, Cultural and Media Studies: The key Concepts (4th ed.). London, New York: Routledge.

Hill, K., Thomas, K., AbouZahr, C, Walker, N., Say, L., Inoue, M., \& Suzuki, E. (2007). Estimates of Maternal Mortality Worldwide between 1990 and 2005: An Assessment of Available Data. Lancet, 370(9696), 1311-1319.

Hodgetts, D., \& Chamberlain, K. (2006). Developing a Critical Media Research Agenda for Health Psychology.Journal of Health Psychology, 11(2)317-327.

Iliyasu, Z., Abubakar, I. S, Galadanci, H. S., \& Aliyu, M. H. (2010). Birth Preparedness, Complication, Readiness and Father's Participation in Maternity care in a Northern Nigerian community. African Journal of Reproductive Health, 14(1), 21-32.

International Planned Parenthood Federation. (2004). IPPF Fact Card No. 2, London: IPPF.

Iyaniwura, A., \& Yussuf, Q. (2009). Utilization of Antenatal care and Delivery Services inSagamu, South Western Nigeria, Africa. Journal of Reproductive Health, 13(3), 111-122.

Kistiana, S. (2009). Socio-Economic and Demographic Determinants of Maternal Health Care Utilization in Indonesia. MA Thesis, The Flinders University of South Austriala, Adelaide.

Janz, N. K., \& Becker, M. H. (1984). The Health Belief Model: A Decade Later. Health Education Quarterly, 11, 1-47.

Jensen, K. B. (2012). The Qualitative Research Process. In K. B. Jensen (Ed.). A handbook of Media and Communication Research: Qualitative and Quantitative Methodologies (2nd ed.). London, New York: Routledge Taylor \& Francis Group.

Jung, L. S. (2010). Trust in Nurses: A Qualitative Study on Prenatal Hispanic Women. PhD. Dissertation, George Mason University, Fairfax, VA.

Kruegar, R. A., \& Casey, M. A. (2000). Focus Groups: A practical guide to Applied Research, (3rd ed.). Thousand Oaks, CA: Sage. 
Kakogawa, J., Sadatsuki, M., Ogaki, O., Nakanishi, M., \& Minoura, S. (2011). Effects of Social Service Prenatal care Utilization on Prenatal outcomes among women with Socio economic problems in Tokyo Metropolitan Area. Retrieved from http://www.ncbi .nim.nihi.gov/pmc/articles/pmc 3202094/? Tool=pubmed

Legard, R., Keegan, J., \& Ward, K. (2003). In depth interview. In J. Ritchie \& J. Lewis (Eds.). Qualitative Research Practice: A guide for Social Science Students and Researchers. London, Thousand Oaks, New Delhi: Sage Publications.

Lindolf, T. R., \& Taylor, B. C. (2011). Qualitative Communication Research Methods (3rd ed.). Thousand Oaks, California, London, New Delhi: Sage Publication Inc.

Magoma, M., Merialdi, M., Campbell, O. M., Cousens, S., \& Fillippi, V. (2011). How much time is available for Antenatal Care Consultation? Assessment of the Quality of Care in rural Tanzania. BMC Pregnancy Childbirth, 11(64).

Massey, P. (2011). Reducing Maternal Mortality in Senegal: Using GIS to Identify Priority Regions for the Expansion of Human Resources for Health. World Health \& Population, 13 (2).

May, T. (2001). Social Research Issues, methods and Process (3rd ed.). Buckingham: Open University Press.

Mohammed, I. Z. (2005). Knowledge and Attitude of Hausa Men Towards Family Planning. Journal of Social and Management Sciences, 9,107-134.

Morton, T. A., \& Duck, J. M. (2001). Communication and Health Beliefs: Mass and Interpersonal influences on perceptions of risk to self and others. Communication Research, 28(5), 602-626.

Mugweni, L. (2009). Explaining Prenatal Health Promotion Eexperiences of recent Immigrant Women. MA Nursing Thesis, University of Manitoba, Winnipeg, Canada.

National Population Commission. (NPC). Nigeria and ICF Macro (2009). Nigeria Demographic and Health Survey, (NDHS 2008), Abuja, Nigeria: National Population Commission and ICF Macro.

National Millennium Development Goals (MDGs) Report. (2004). NARHS: National HIV/AIDS \& Reproductive Health Survey (NARHS).

Navaneetham, K., \& Dharmalingam, A. (2002). Utilization of Maternal Healthcare Services in Southern India. Social Science \& Medicine, 55(10), 1849-1869.

Ngilangwa, D. (2007). The Role of the Media in HIV prevention trials, Moshi, Tanzania: Kilimanjaro Christian Medical Centre.

Nuraini, E., \& Parker, E. (2005). Improving Knowledge of Antenatal Care Among Pregnant Women: A Field Trial in Central Java, Indonesia. Asia Pacific Journal of Public Health, 17(1), 3-8. 


\section{Macrothink}

Journal of Social Science Studies

ISSN 2329-9150

2014, Vol. 1, No. 2

Patton, M. Q. (2002). Qualitative Research and Evaluation Methods (3rd ed.). Thousand Oaks, CA: Sage.

Paek, H., Lee, B., Salmon, C., \& Witte, K. (2008). The contextual effects of Gender norms, Communication and Social Capital on Family Planning Behaviors in Uganda: A multilevel Approach. Health Education Behavior, 35(4), 461-477.

Ragupathy, S. (1996). Education and the Use of maternal health care in Thailand, Social Science and Medicine, 43, 459- 471.

RaatiKainen, K., HeisKanen, N., \& Heinonen, S. (2007). Under Attending Free Antenatal Outcomes. BMC Public Health, 7, 268

Ritchie, J. (2003). The Application of Qualitative Methods to Social Research. In Ritchie, S. J. \& Lewis, J. (Eds.). Qualitative Research Practice: A Guide for Social Science Students and Researchers. London, Thousand Oaks, New Delhi: Sage Publication.

Royston, E., \& Armstrong, S. (1989). Preventing of Maternal Mortality. Geneva: WHO.

Sabitu, K. (2004). Socio-Cultural context of Reproductive Health and Gender issues in Sokoto State. Report submitted to UNFPA, Nigeria.

Simkhada, B., Teijingen, E. R., Porter, M., \& Simkhada, P. (2008). Factors Affecting the Utilization of Antenatal Care in Developing Countries: Systematic Review of the Literature. Journal of Advance Nursing, 61(3), 244-60.

Simkhada, B. O., Van Teijlingen, E. R, Porter, M., \& Simkhada, P. (2006). Major Problems and Key Issues in Maternal Health in Nepal. Kathmandu University Medical Journal, 4(2), 258-263.

Singh, L., Rai, R. K., \& Singh, P. K. (2012). Assessing the Utilization of Maternal and Child Health Care among Married Adolescent Women: Evidence from India. Journal of Biosocial Science, 44(1), 1-26.

Sood, S., Sengupta, M., Shefner-Rogers, C. L., \& Palmer, A. (2009). Impact of Siaga Maternal and Neonatal Communication Campaign on Knowledge of Danger signs and birth preparedness in West, Java, Indonesia. Journal of Health and Mass Communication, 1(1), 68-81.

Stecher, V. J., \& Rosenstock, I. M. (1997). The Health Belief Model. In Glanz, K., Lewis, F. M. \& Rimer, K. (Eds.). Health Behaviour and Health Education: Theory, Research and Practice (2nd ed.). San Francisco: Jossey- Bass.

Sword, W. (2003). Prenatal Care use among Women of Low Income: A Matter of Taking Care of Self. Qualitative Health Research, 13(3), 319-332.

Thornson, E. (2006). "Print news and Health Pschology." Journal of Health Psychology, $11(2)$.

Taylor, C. R., Alexander, G. R., \& Hepworth, J. T. (2005). Clustering of U.S Women 
Receiving no Prenatal Care: Differences in Pregnancy Outcomes and Implications for targeting Interventions. Maternal and Child Health Journal, 9(2), 125-132.

Thompson, J. E., \& Walsh, L. V. (1990). The Hstory of Prenatal Care: Cultural, Social and Medical Context. In Merkatz, I.R, Thompson, J. E. (Eds.), New Perspectives on Prenatal Care (pp. 9-30). New York: Elsevier.

The Millennium Development Goals Report. (2010) mdgs.un.org.

Umar, M.A. (2006). Focus Group Discussion. In Adamu, Y. M, Mohammed, H. \& Dandago, K. I, (Eds.). Readings in Social Science Research (pp. 144-150). Kano: Adamu Joji Publishers.

Umar, M. A. (2006). Focus Group Discussion. In Adamu, Y. M, Mohammed, H. \& Dandago, K. I, (Eds.). Readings in Social Science Research. (pp. 144-150). Kano: Adamu Joji Publishers.

United Nations Population Fund (UNFPA). (2004). State of the World's Population 2004: Maternal Health. New York.

United Nations. (2009). UN Millennium Development Goals. Retrived from http:/www.un.org/millennium

United Nation Development Programme (UNDP). (2006) Human Development Report 2003. A Publication of UNDP Nigeria Country Report.

United States Department of Health \& Human Services. (2000). Healthy People 2010. National Health Promotion and Disease Prevention Objectives. Washington DC: US Government Printing Office.

UNFPA. (2001). United Nations Population fund. Contextual factors influencing people's health seeking behaviour, module 2: socio-cultural aspects of reproductive health.

Valente, T. W., \& Saba, W. P. (1998). Mass Media and Interpersonal Influence in a Reproductive Health Communication Campaign in Bolivia. Communication Research, 25(1), 96-124.

Walford, H. H., Trinh, S., Wiencrot, A., \& Lu, M. C. (2011). What is the Role of Prenatal Care in reducing Racial and Ethnic disparities in Pregnancy? In Handler, A., Kenelly, J. \& Peacock, N. (Eds.). Reducing Racial, Ethnic Disparities in Reproductive and Perinatal Outcomes: The Evidence from Population - Based Interventions (pp. 151-179). New York: Springer Science and Business Media, LLC.

Wimmer, D. R., \& Dominick, J. R. (2011). Mass Media Research: An Introduction. USA: Wadsworth.

World Bank. (2009). Making services work for poor people. Report on Nigeria Budgetary Allocation to Health sector, Development Report from West African Office: World Bank. 


\section{Macrothink}

Journal of Social Science Studies

ISSN 2329-9150

2014, Vol. 1, No. 2

World Health Organisation. (2005). Increasing Media Awareness on Maternal and Child Health Issues: Report of a Regional Workshop. Bangkok, 7-18 February 2005. WHO Project: ICP MPS 001, World Health Organisation, Regional Office for Sourth-East Asia.

World Health Organisation. (2007). Maternal Mortality in 2005: Estimates Developed by WHO, UNICEF, UNFPA, and the World Bank. Geneva: WHO.

WHO, UNICEF, \& World Bank. (2010). Trends in Maternal Mortality 1990 to 2008. Geneva: WHO.

WHO \& UNICEF. (2003). Antenatal Care in Developing Countries and Different Promises, Achievements and Missed Opportunities: An Analysis of Trends, Levels and Differentials: 1990-2001. Geneva, New York: WHO \& UNICEF.

WHO/UNICEF/UNFPA. (2004). Maternal Mortality in 2000: Estimates Developed by WHO, UNICEF and UNFPA, Geneva World Health Organisation, 2004.

Wright, K. B., Sparks, L., \& O'Hair Dan, H. (2008). Health Communication in the $21^{\text {st }}$ Century. USA, UK, Australia: Blackwell Publishing.

Wall, L. L. (1998). Dead Mothers and Injured Wives: The Social Context of Maternal Morbidity and Mortality among the Hausa of Northern Nigeria. Studies in Family Planning, 29, 321-359.

\section{Copyright Disclaimer}

Copyright reserved by the author(s).

This article is an open-access article distributed under the terms and conditions of the Creative Commons Attribution license (http://creativecommons.org/licenses/by/3.0/). 